\title{
Curating in the Gap: Inhabiting the Digital Space
}

\author{
Heidi M. Aishman \\ University of Reading \& \\ University of the Arts, Zurich \\ Ashrise, Rosemary Lane, Thorpe \\ Surrey TW20 8QE, UK \\ heidi@heidiaishman.com
}

\section{INTRODUCTION}

This presentation asks if digital spaces such as social media platforms, live streams, and cell phone apps can function as curated visual arts exhibition spaces. If so, do these digital spaces offer an opportunity for curators and existing visual arts institutions to connect with groups that are currently marginalised by the museum/gallery exhibition structure? By inhabiting the digital space (the gap) marginalised groups can have a place of display that does not support the binary that historically separates the notion of the arts institution and those on the outside of that existing structure. Can the gaps between contemporary art institutions and marginalised groups become powerful structures that can serve not just as places of display, but also as primary generators of cultural meaning in a diverse and globalised world? How can emerging technologies become tools of self-representation for those who do not usually have access to current exhibition structures? This presentation aims to form a critical theoretical framework for how to curate within that gap.

\section{BEYOND DISPLAY: DIALOGUE WITHIN "THE GAP"}

Lisa Blackman, Professor in Media and Communications, Goldsmiths College, stated "The experience of the digital era is today often argued to move beyond forms of representation involving corporeality of perception with artists, practitioners and designers to explore the many intersections between affect, emotion, sensation and action." This research began with an exhibition I curated that included video chat to allow marginalised groups to be present during opening receptions of exhibitions that included their work. The exhibition focus moved from the display of the work to the affect and emotion of interaction online. By being able to virtually participate in their own exhibition, the opening itself became a generator of the meaning of the work in the lives of the artists and the viewers. The cross-continental dialog during the opening created a new set of complex and interdependent collaborative meanings that has continued to evolve even after the closing of the exhibition.

By integrating social media and online tools, an exhibition or collaboration extends beyond the geographical location of the established exhibition space, and opens the possibility for an "interface between the domain of information (the digital) and embodied human experience". (Castells, 2008) With a deeper curatorial investigation through the practice of media theory and affective registers, the human experience transmitted through social media and online platforms is made tangible. As Manual Castells stated, "the spread of affordable information and communication technologies, such as mobile phones and the internet, has broadened the public sphere; and shifted it from the institutional realm to the new communication space." There is a need for the established institutional structure of visual exhibitions to integrate online tools based on how the larger pubic sphere is using them, not on how the institution would like the public to use them to better serve the current structure (for example using a Facebook page as simply another platform to inform the public about what's on in hopes of generating more membership). 


\section{INTEGRATION OF NEW TECHNOLOGIES: RESTRUCTURING CURATORIAL PRACTICE}

For curatorial practice to fully utilise online and digital platforms they need to be included in the infrastructure, the foundations of building an exhibition project. Technologies used to generate online spaces of exchange, in whatever form can no longer be and "add on" or in addition to the traditional exhibition structure.

New media, digital media, and online platforms can only open up possibilities when those possibilities become normalised, a given, a fundamental. In the current climate of what we call the experience economy, interaction, input, commentary and access to these engagements are expected by those who currently participate in arts events/activities. Curatorial practice is no longer limited to its geographic and physical parameters, and so underserved communities and marginalised groups can also benefit from these new platforms of engagement.

"The Gap" between exhibition spaces and the marginalised can be created by:

a) Facetime/Skype opening avenues for access;

b) Online forums for collaboration like Instagram;

c) Looking at gaming platforms, YouTube, as forms of engagement to be mined.

\section{REFERENCES}

Blackman, L. (2013, December 9). Conference: Affective Experiences in Art, Design \& Research. Parasol unit foundation for contemporary art 14 Wharf Road / London / N1 7RW.

Castells, M. (2008). The New Public Sphere: Global Civil Society, Communication Networks, and Global Governance. The Annals of the American Academy of Political Social Science, 616(1), pp. 78-93.

Hansen, M. B. (2004). New Philosophy for New Media. Cambridge, MA: MIT Press.

Jenkins, H., Ford, S., and Green, J. (2013). Spreadable Media: Creating value and meaning in a networked culture. New York: New York University Press.

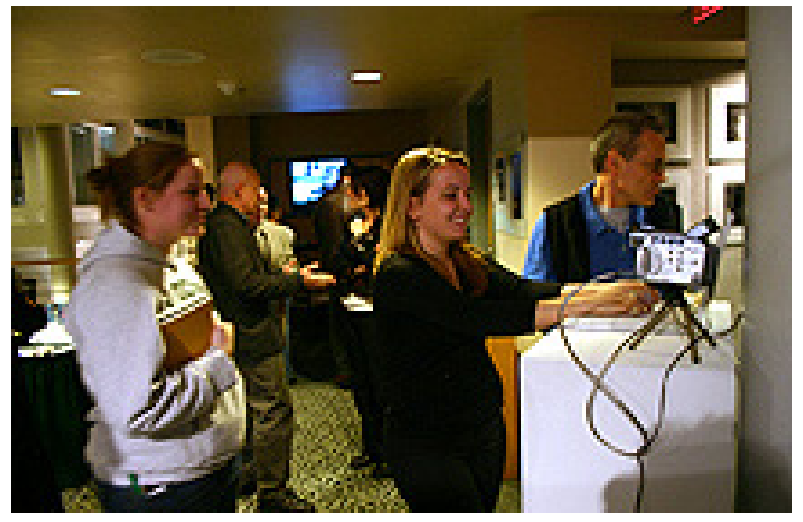

Figure 1: Live Web Chat. Ph15 Students in Buenos Aires to Babson College, USA 2006. Photo credit: Heidi Aishman.

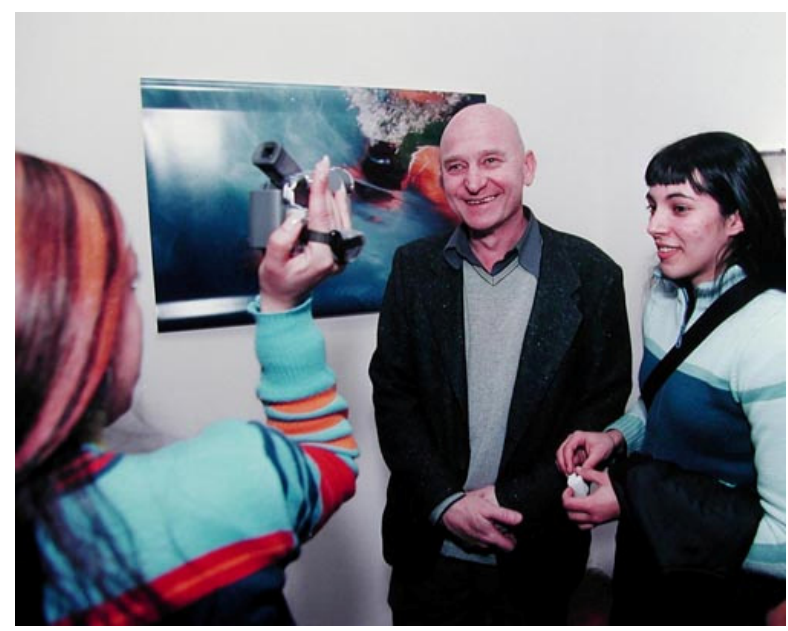

Figure 2: Live Web Chat, Sonoridad Amarilla Gallery, Buenos Aires, 2004. Photo credit: Steve Aishman.

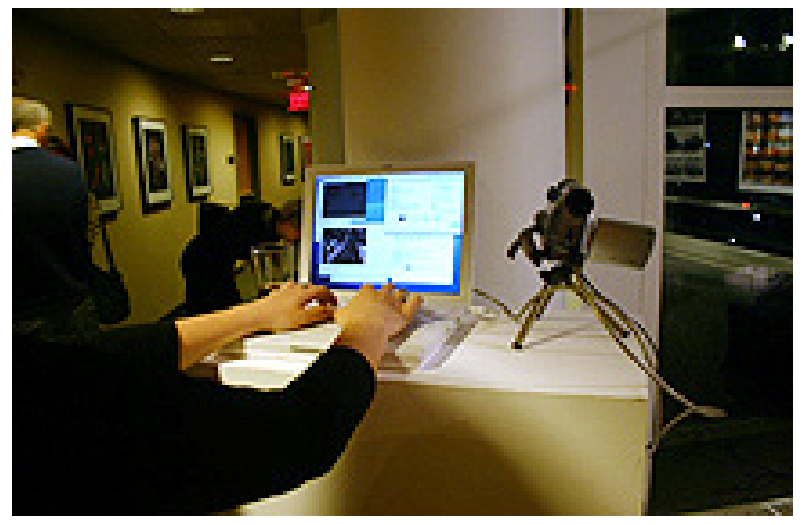

Figure 3: Live Web Chat. Ph15 Students in Buenos Aires to Babson College, USA 2006.

Photo credit: Heidi Aishman. 